\title{
Síndrome Alcoólica Fetal: Uma abordagem reflexiva da Psicopedagogia no contexto da Educação Básica
}

\author{
Henrique Miguel de Lima Silva ${ }^{1}$, Symara Abrantes Albuquerque de Oliveira Cabral ${ }^{2}$, \\ Maria Carmem Batista de Alencar ${ }^{3}$, Edgley Gonçalves Alves Segundo ${ }^{4}$, Edivânia Maria Leite da Silva ${ }^{5}$
}

\begin{abstract}
Resumo: O presente trabalho propõe-se a partir da abordagem sociointeracionista de autores como Piaget (1979), Vygotsky (1989), dentre outros, que partilham da análise do indivíduo na perspectiva dialógica, inserir dentro da educação básica a temática da síndrome alcoólica fetal com base em práticas reflexivas, no intuito de promover um desenvolvimento crítico do educandos acerca das relações entre álcool e desenvolvimento cognitivo humano. Trata-se de um relato de experiência de atividade formativa realizada com docentes do ensino fundamental, com abordagem da temática, de modo a provocar a reflexão para prática. Dessa maneira, buscar compreender os modos de interação na sociedade contemporânea propicia a construção de métodos e pesquisas que possam explorar o comportamento humano e, por conseguinte, desenvolver as relações sociais como um todo, tomando por base a observação de ação realizada.
\end{abstract}

Palavras-chave: síndrome alcoólica fetal, psicopedagogia, sociedade.

\section{Fetal Alcohol Syndrome: A reflective approach to Educational Psychology in the Basic Education context}

\begin{abstract}
Absract: This paper proposes from sociointeractionist approach of authors such as Piaget (1979), Vygotsky (1989), among others, who share the analysis of the individual in the dialogical perspective, insert into the basic education the issue of fetal alcohol syndrome based in reflective practices in order to promote a critical development of the students about the relationship between alcohol and human cognitive development. This is an account of the formative activity experiment conducted with teachers of primary school, with the thematic approach, so as to cause reflection to practice. Thus, seeking to understand the modes of interaction in contemporary society provides the construction methods and research to explore human behavior and therefore develop social relations as a whole, based on the observation of the action taken.
\end{abstract}

Keywords: fetal alcohol syndrome, educational psychology, society.

\section{Introdução}

Desde os tempos mais remotos da vida humana, bem como seu desenvolvimento, diversas foram às influências externas que, por sua vez incorporaram à filogênese. A este fenômeno, segundo, Tomasello (2003), atribui a esse fator ontogenético um valor constitutivo dos comportamentos e, ao mesmo tempo, considera as bases cognitivas existentes para o desempenho de diversas funções.

\footnotetext{
${ }^{1}$ Doutorando em Linguística - Universidade Federal da Paraíba - João Pessoa - PB. E-mail: henrique.miguel.93@ hotmail.com.;

${ }^{2}$ Doutoranda em Ciências da Saúde - Faculdade de Ciências Médicas da Santa Casa de São Paulo. E-mail: symara_abrantes@hotmail.com;

${ }^{3}$ Mestranda em Sistemas Agroindustriais - Universidade Federal de Campina Grande. E-mail: carmemsjp@ @otmail.com;

${ }^{4}$ Graduação em Contabilidade - Faculdade de Filosofia, Ciências e Letras de Cajazeiras - PB. E-mail: segundo_cz@hotmail.com;

5 Graduação em Administração - Universidade Federal de Campina Grande. E-mail: edivaniamaria.leite@ gmail.com.
} 
Dentro das pesquisas voltadas para o desenvolvimento humano, busca-se compreender quais as alterações que o álcool proporciona ao feto, bem como a mãe, para, em seguida, compreender como o desenvolvimento crítico/reflexivo a partir da ação psicopedagógica no contexto educacional, em especial, para a educação básica.

A síndrome alcoólica fetal é adquirida pelo feto por meio da ingestão do álcool por parte da mãe em períodos de gestação. Neste período, segundo Costa (2012, p. 35), “o etanol é transferido para a criança através do leite materno, na produção de $2 \%$ da alcoolemia da mãe”. Aliado a este fator, ocorre a diminuição da produção de leite materno, bem como alterações nos padrões de desenvolvimento cognitivo.

\section{Metodologia}

Trata-se de um relato de experiência de atividade formativa realizada com docentes do ensino fundamental, com abordagem da temática, de modo a provocar a reflexão para prática na perspectiva da atuação interdisciplinar na abordagem de educação em saúde e fomento à prática pedagógica.

Deste modo, foi realizada uma oficina junto a 5 (cinco) professores, que através de uma abordagem qualitativa, promoveram a discussão do tema e posterior análise da aplicabilidade prática dos conceitos obtidos. Todas as discussões foram fundamentadas de modo a promover o conhecimento científico a partir de uma análise bibliográfica e discussão da necessidade de mudança de prática com a inserção das informações sobre os riscos do alcoolismo, de modo que, foi articulada uma atividade com foco em metodologias ativas para aplicação com crianças do Ensino Fundamental, como produto do referido trabalho.

\section{Resultados e Discussões}

A partir da fundamentação teórico-científica, observou-se que alterações como diformismo facial, alterações na organogênese, risco de morte e desenvolvimento cognitivo 
Id on Line Revista Multidisciplinar e de Psicoloqia

Id on Line Multidisciplinary Journal and Psycology

atípico, dentre outros fatores, comprometem as interações que podem ser desenvolvidas nos mais variados contextos, em especial na fase de educação infantil, período em que a criança necessita desenvolver suas habilidades múltiplas por meio da interação.

Segundo Tango (Apud, COSTA, 2012):

A SAF ou Síndrome Fetal Alcoólica, ou ainda efeito Alcoólico Fetal, é a 'manifestação de defeitos neonatais de crescimento, mentais e físicos associados ao alto consumo de álcool pela mãe durante a gestação' e foi descrita pela primeira vez em 1968, por Lemoine e colaboradores.

No início acreditava-se que essa síndrome poderia estar associada aos modelos de desenvolvimento familiares menos favorecidas socioeconomicamente por meio da crença que essas camadas consumiam em maior quantidade bebidas alcoólicas durante a gestação, fato desmistificado em pesquisas futuras. Sabe-se que, de fato, essas alterações anatômicas e cognitivas comprometem o desenvolvimento da criança e de suas interações por meio de alterações comportamentais.

As principais características anatômicas, segundo Costa (2012), da Síndrome Alcoólica Fetal são: cabeça pequena; prega epicânticas; facies plana; philtro indefinido; nasio rebaixado; pequena abertura nos olhos; nariz curto; lábio superior curto; e microcefalia.

Essas modificações alteram a produção linguística bem como a respiração, podendo alterar a interação da criança por perceber-se como diferente de seu coletivo no contexto da educação infantil, fase em que as mesmas necessitam interagir, como um dos postulados da Educação Infantil, segundo os PCN's (1998).

Em termos cerebrais, as alterações, de acordo com a referida autora, são: a) Hipocampo - aprendizagem e memória; b) Gânglios de base - movimento; c) Cerebelo equilíbrio, postura e emoções; d) Hipotálamo - temperatura corporal, fome, emoções, sede e ritmos biológicos; e) Tálamo - integração sensorial e integração motora; f) Córtex pensamento, movimento voluntário, linguagem, julgamento e percepção; g) Área septal emoção; h) Corpo caloso - ligação entre o hemisfério esquerdo e hemisfério direito.

Essas alterações comprometem a linguagem, a noção de espaço, questões sensóriomotoras e, por conseguinte, necessita de uma equipe multidisciplinar para diagnosticar e tratar as crianças com essa síndrome. Aliado a essa equipe, inclui-se o psicopedagogo enquanto profissional responsável pelo desenvolvimento de pesquisas e métodos nos processos de ensino/aprendizagem. 
O diagnóstico auxilia na compreensão de como essa questão de ordem externa modifica os padrões internos e, por conseguinte, a interação; aprendizagem e até mesmo o desenvolvimento embrionário.

Salienta-se, ainda que, o padrão de Síndrome Alcoólica Fetal é específica para cada caso, ou seja, as crianças não tendem a apresentar todas as características que dessa síndrome; o que, muitas vezes, dificulta o tratamento adequado.

Para Costa (2012) um tratamento adequado promove um desenvolvimento integral das potencialidades desses indivíduos. Aliado a isso, a escola tem um papel de promover essa formação efetiva. A própria Lei de Diretrizes e Bases da educação brasileira- LDB visa articular vários aspectos da vida humana como: saúde, vida social, ciências, matemáticas, sexualidade, etc. além disso, a LDB, através da Lei $\mathrm{n}^{\circ}$ e da Lei $\mathrm{n}^{\circ}$ 9.3394/96, afirma em seu segundo artigo que a educação deve ser:

Dever da família e do estado, inspirada nos princípios de liberdade e nos ideais de solidariedade humana, tem por finalidade o pleno desenvolvimento do educando, seu preparo para o exercício da cidadania e sua qualificação para o trabalho.

Ao nos depararmos com os PCN's e a Lei de diretrizes e Bases da educação brasileira percebe-se a grande preocupação não só com a formação científica dos cidadãos. Esta, por mais eficiente que pareça ser, não dá conta de todas as questões inerentes ao ser. É preciso ir além, com uma formação social que possibilite ao cidadão uma reflexão crítica sobre sua sociedade. É isto que fica evidente quando lemos e relemos a LDB e os PCN's.

No que envolve essa formação integral, Freire (1996), bem como Antunes (2000), promovem uma reflexão sobre o papel da escola enquanto instância que prepara o indivíduo para a vida.

Dentro da equipe multidisciplinar que diagnostica a Síndrome Alcoólica Fetal, a psicopedagogia, juntamente, com os demais profissionais, auxilia de forma reflexiva e preventiva por meio da aplicação de testes de aprendizagem e, em seguida, no desenvolvimento de diversas estratégias de reflexão com os próprios alunos e pais dentro do contexto educacional.

Compreender essa dinâmica do álcool dentro da sociedade e sua recorrência faz com que a Psicopedagogia passe a ser componente dessa equipe multidisciplinar ao promover a reflexão enquanto elo de formação social da própria mente (VYGOTSKY, 1987). 
Aliado a este fator, segundo Severino (1997), cabe a escola promover essa reflexão filosófica dos paradigmas comportamentais humanos para que os educandos sejam autores de sua história de forma crítica. Esta formação, com base no psicopedagogo, promoverá uma mudança no eixo das ações dos comportamentos e até mesmo no modo de observar o mundo.

Essa leitura dinâmica e ativa da Síndrome Alcoólica Fetal dentro do contexto escolar reafirma a indispensável relação entre escola e sociedade; ou seja, que ambas devem estar associadas no intuito de promover o desenvolvimento social crítico.

A Psicopedagogia, no contexto da educação básica, ajuda na promoção do conhecimento sobre as diversas estruturas da formação cognitiva humana, bem como na compreensão dos fenômenos sociais que implicam alterações na mesma. A Síndrome Alcóolica Fetal, quando abordada de forma adequada, permite uma melhor compreensão de como as práticas "sociais" acarretam sérios riscos aos bebês, futuros cidadãos que, por sua vez, terão sua essência modificada pelo uso indiscriminado do álcool.

Dentro desse contexto escolar, deve-se promover uma maior interação a respeito das temáticas sociais, transformando, com base na ação psicopedagógica, a escola numa espécie de roda viva, em constante mudança e ainda somar as potencialidades, subtrair dificuldades e multiplicar cidadãos críticos (WARSCHAUER, 1993).

Dessa maneira, a Psicopedagogia funciona como um elo crítico/reflexivo dentro do espaço escolar por desenvolver estratégias que relacionem os problemas sociais ao campo educacional para, em seguida, promover um desenvolvimento social efetivo.

Tomando por base tais afirmações, os participantes do grupo de professores elaborou uma atividade para aplicabilidade prática dos conceitos a partir das metodologias ativas, de modo a ser utilizada junto aos alunos do Ensino Fundamental, de modo a abordar o tema de forma lúdica e compreensível, concernente ao entendimento correlato à idade das crianças, deste modo propôs-se a atividade do "certo ou errado e consequência", na qual as crianças recebem figuras de ações que devem ser classificadas como certas ou erradas e posteriormente analisando-as junto a professora frente a discussão em roda, quais as consequências de cada uma delas.

Após aplicação da atividade ocorreu novo encontro, de modo que os professores relataram suas experiências, que foram, com unanimidade, positivas, nas quais os alunos reconhecem o alcoolismo como "errado" e expressaram como consequências: perda de tempo, 
perda de familiares, doenças e violência. E, durante a discussão as professoras, ao abordarem com seus alunos a Síndrome Alcoólica Fetal notaram o desconhecimento dos alunos sobre a possibilidade de a criança ser prejudicada.

\section{Considerações Finais}

As dinâmicas sociais modificaram diretamente os modos de interação do homem com o meio e com seus semelhantes. $\mathrm{O}$ álcool passa a ser um coadjuvante que coloca em risco o desenvolvimento típico das crianças por causar a Síndrome Alcóolica Fetal. Esta, por sua vez, causa alterações cognitivas, anatômicas e comportamentais de diversos níveis e graus.

Compreender como a Síndrome Alcóolica Fetal pode ser trabalhada de forma crítica com base nos fundamentos da psicopedagogia institucional pode promover uma redução dessa síndrome e ainda formar cidadãos críticos e protagonistas de suas histórias.

Dessa maneira, a Psicopedagogia se insere nessa equipe multidisciplinar com o objetivo de promover uma reflexão e aprendizagem a respeito da Síndrome Alcóolica Fetal dentro do contexto da educação básica que é, por sua vez, um meio para formação crítica do conhecimento e das relações sociais, de modo dinâmico e participativo. Somente assim é que poderemos desenvolver a consciência crítica nos educandos.

A este respeito, acredita-se que as reflexões promovidas pelo campo da psicopedagogia institucional promovem, juntamente com a equipe docente, estratégias que tem como base participação ativa dos educandos no contexto da interação possibilitam a ampliação de uma consciência crítica dos estudantes enquanto autores de sua própria história.

Dessa maneira, acredita-se que abordar questões da síndrome alcoólica fetal na educação infantil promove a construção da uma moral e auxilia no desenvolvimento da personalidade por meio da análise de situações, infelizmente, cotidianas e, a partir disso, modificar o paradigma existente nas gerações futuras por meio do conhecimento. 
Id on Line Revista Multidisciplinar e de Psicoloqia

Id on Line Multidisciplinary Journal and Psycology

\section{Referências}

ANTUNES, Celso. A teoria das Inteligências Libertadoras. 2. ed. Petrópolis: Vozes, 2000.

Como desenvolver as competências em sala de aula. Petrópolis: Vozes, 2001.

Alfabetização emocional. $10^{\circ}$ ed. Petrópolis: Vozes, 2003.

BRASIL, L.D.B.E.N Lei de Diretrizes e Bases da Educação Nacional. Lei 9394 de 20 de dezembro de 1996, Brasília: DDV, 23 de novembro 1996

FREIRE, Paulo. Pedagogia da Esperança. 13 Ed. Rio de Janeiro: Paz e Terra, 1992.

FREIRE, Paulo. Pedagogia da Autonomia. Saberes Necessários à Prática Educativa. São Paulo: Paz e terra, 1996.

SEVERINO, Antônio Joaquim. Filosofia da Educação: construindo a cidadania. São Paulo, FTD, 1994.

SOUZA, Maria de Lurdes de. Apud- KRIEGL. Leitura um Desafio Sempre Atual. São Paulo: Contexto, 1993.

VYGOTSKY, L. S. A Formação Social da Mente. São Paulo, Martins Fontes, 1987.

WARSCHAUER, Cecília. A roda e o registro, uma parceria entre professor, alunos e conhecimento. Rio de Janeiro: Editora Paz e Terra, 1993.

Como citar este artigo (Formato ABNT):

SILVA, H.M.L.; CABRAL, S.A.A.O.; ALENCAR, M.C.B.; SEGUNDO, E.G.A.; SILVA, E.M.L. Síndrome Alcoólica Fetal: Uma abordagem reflexiva da Psicopedagogia no contexto da Educação Básica. Id on Line Revista Multidisciplinar e de Psicologia, Out-Nov. de 2016, vol.10, n.31, Supl 3, p. 01-07. ISSN 1981-1179.

Recebido: 24/10/2016

Aceito: 25/10/2016 